\title{
FATORES QUE DEFINEM AS CONDIÇÕES DE TRABALHO DE AVICULTORES E SUINOCULTORES DO OESTE CATARINENSE
}

\author{
Cibeli Borba Machado* \\ Nathália Helena Fernandes Laffin** \\ Rafael Franzoni Maioral*** \\ Rafael Tezza**** \\ Valério Alécio Turnes ${ }^{* * * * *}$ \\ Julio da Silva Dias ${ }^{* * * * * *}$
}

RESUMO: A agricultura catarinense, fortemente representada no Oeste de Santa Catarina, constitui-se como um dos principais pilares da economia do Estado, gerando riquezas e mudanças sociais. Neste cenário, o presente trabalho realiza uma análise social das relações e condições de trabalho e de saúde dos agricultores vinculados à produção industrial de suínos e aves desta região e como estas interferem no bem -estar e na sustentabilidade do complexo agroalimentar do Oeste catarinense. Desta forma, o objetivo geral deste estudo consiste em analisar se há diferença significativa nas condições de trabalho encontradas nesses dois grupos de produtores. De acordo com os dados analisados, verificou-se que as questões referentes à relação com a empresa integradora revelam melhor alinhamento com os suinocultores, sugerindo que de fato há diferenças entre os dois grupos na percepção que esses possuem das empresas integradoras e, também, o grau de satisfação geral e financeiro. Porém, tais fatores não necessariamente geram maior cansaço ou depressão significativa por parte dos avicultores.

PALAVRAS-CHAVE: Avicultores; Condições de trabalho; Suinocultores; Teste de associações Qui-quadrado.

\section{FACTORS THAT DEFINE LABOR CONDITIONS OF POULTRY}

\footnotetext{
"Administradora, Mestre em Administração da Universidade do Estado deSanta Catarina (ESAG/UDESC); E-mail: cibelimachado@yahoo.com.br

${ }^{*}$ Contadora, Doutoranda do Programa de Pós-Graduação em Controladoria e Contabilidade da Faculdade de Economia, Administração e Contabilidade de Ribeirão Preto da Universidade de São Paulo (FEARP-USP).

*** Administrador, Mestre em Administração da Universidade do Estado de Santa Catarina (ESAG/UDESC).

***** Docente dos Programas de Graduação e Pós-Graduação em Administração de Empresas da Universidade do Estado de Santa Catarina (ESAG/UDESC).

***** Docente do Programa de Graduação em Administração Pública da Universidade do Estado de Santa Catarina (ESAG/UDESC).

******* Docente dos Programas de Graduação e Pós-Graduação em Administração de Empresas da Universidade do Estado de Santa Catarina (ESAG/UDESC).
} 


\title{
AND SWINE BREEDERS IN THE WESTERN REGION OF SANTA CATARINA, BRAZIL
}

\begin{abstract}
Agriculture in the western region of the state of Santa Catarina, Brazil, is one of the main assets in the economy of the state featuring great social changes and wealth production. Current paper provides a social analysis of labor and health relationships and conditions of farmers in the industrial production of poultry and swine and their influence on the welfare and sustainability of the agriculture-food complex of the region. It discusses whether there are significant differences in labor conditions between the two groups. Data revealed that issues on relationships with the company showed better integration with swine breeders. There are differences between the two groups in their perception on the integrating companies and on their general and financial satisfaction levels. The factors, however, fail to produce fatigue or significant depression on poultry breeders.
\end{abstract}

KEY WORDS: Poultry Breeders; Labor Conditions; Swine Breeders; $\chi^{2}$ test.

\section{INTRODUÇÃO}

O Oeste de Santa Catarina, polo agroindustrial do Estado, principalmente na produção de carnes de suínos e frangos, se constitui em um dos pilares da economia catarinense. Segundo o SEBRAE (2010), a pecuária responde por $48 \%$ do rebanho catarinense de suínos e por $37 \%$ de frango. O crescimento das agroindústrias ampliou o mercado de trabalho e transformou-se na base da economia na região, juntamente com a agricultura.

De acordo com Coletti (2009), a agricultura familiar da região Oeste é apontada como setor determinante para o desenvolvimento do parque agroindustrial da região. Os suinocultores e avicultores firmam contrato com as agroindústrias, vendendo a elas os animais, e as empresas fornecem insumos e tecnologia, em um sistema de integração.

Foi neste cenário agrícola que se realizou a pesquisa de análise das relações e condições de trabalho e de saúde dos agricultores vinculados à produção industrial de suínos e aves, e como estas interferem no bem-estar e reprodução social dessa categoria e na sustentabilidade do complexo agroalimentar do Oeste catarinense. 
A problemática da pesquisa surgiu a partir da observação de um grande contraste entre os fatores estudados, os quais parecem evidenciar condições de trabalho e sociais muito piores por parte dos avicultores em relação aos suinocultores. Diante dessa percepção, justifica-se a realização da pesquisa com vistas a analisar se há, de fato, diferença significativa nos resultados encontrados nesses dois grupos de produtores.

Desta forma, o objetivo geral deste estudo consiste em analisar, estatisticamente, por meio do teste de associações qui-quadrado de Pearson, se há diferença significativa nos resultados encontrados nesses dois grupos de produtores.

\subsection{REFERENCIAL TEÓRICO}

\subsubsection{Agricultura Familiar e Agroindústria no Oeste de Santa Catarina}

A organização agrícola, no Estado de Santa Catarina, se deve, principalmente, à construção da Estrada de Ferro São Paulo - Rio Grande, que ligava o Estado de São Paulo ao Rio Grande do Sul, passando pelas terras do Oeste catarinense. Essa construção contribuiu para o processo de povoamento e colonização da região, que se mostrava atrativa pela possibilidade dos colonos se tornarem donos das próprias terras (GOULARTI FILHO, 2007).

Dentre as diversas atividades econômicas exploradas nas terras, destacou-se a agricultura, que, neste período, articulava-se com as tradições, costumes e conhecimentos produtivos dos colonos (MELLO; SCHMIDT, 2003). Os então agricultores se organizavam na produção de diferentes produtos com fins de venda no comércio local. Inicialmente, destacava-se o cultivo de cana-de-açúcar, mandioca, arroz, café e outros. Com o passar do tempo, a área de abrangência foi se expandido para os derivados do suíno e do leite.

Neste cenário, constituiu-se uma economia de subsistência e de comercialização de excedente (GOULARTI FILHO, 2007), fundamentada nas bases familiares, em pequenas propriedades, com os produtos sendo fabricados nas colônias e em comércios de pequenas escalas (DELOS ASSOCIADOS, 2012).

A agricultura familiar constitui-se nos processos produtivos, que são realiza- 
dos por entes da mesma família, no mesmo local de residência; na gestão, realizada por familiares; no capital obtido, que não é repassado a terceiros; e no patrimônio, que será transferido intergeracionalmente para os membros da família (ABRAMOVAY, 1997). Nesse sentido, essa força de trabalho se compõe não apenas no espaço de trabalho, mas também nas relações familiares.

De acordo com Goularti Filho (2007), no período de 1945 a 1962, a economia catarinense ampliou suas bases produtivas com o desenvolvimento das indústrias. Neste momento, as atividades rumam da agricultura familiar e comercial para agroindustriais. Nessa época foram instituídas, também, linhas de crédito para a agricultura como incentivo para permitir a compra de máquinas e insumos modernos. Para Paulilo (1987), esse processo qualificou-se como uma exclusão de diversos produtores da agricultura, pois, ao não conseguir acompanhar as mudanças tecnológicas, foram obrigados a deixar o campo. A partir daí configurou-se um novo cenário, com o crescimento da agroindústria e a diminuição da agricultura familiar.

\subsubsection{Sistemas de Integração}

As agroindústrias tiveram o início de suas atividades de produção utilizando animais fornecidos pelos pequenos produtores. Com a monopolização do capital, ocorreu também um processo de modernização da pequena produção. Ainda que houvesse a venda para os comércios, não havia relações de dependência entre os produtores e terceiros (GOULARTI FILHO, 2007). A partir de então, constituiu-se uma relação que se transformou com o decorrer dos anos e é chamada de integração (DELOS ASSOCIADOS, 2012).

A produção integrada "se caracteriza pelo fornecimento de insumos e assistência técnica ao produtor, e a agroindústria compra toda a produção" (DELOS ASSOCIADOS, 2012, p. 58). Cabe, ao agricultor, acompanhar o desenvolvimento tecnológico e os padrões das integradoras para garantir a permanência no sistema de integração.

O sistema integrado é uma prática constante na agroindústria do Oeste catarinense, principalmente na avicultura e na suinocultura, que permitiu que as empresas se concentrassem apenas na produção do bem final, não precisando ter áreas de 
criação e produção de matéria-prima (DELOS ASSOCIADOS, 2012), e assim passou a ter o controle dos pequenos agricultores.

\section{MATERIAL E MÉTODOS}

\subsection{MÉTODOS DE PESQUISA}

No que diz respeito à metodologia utilizada para a elaboração da pesquisa, este estudo classifica-se, em relação ao seu objetivo, como descritivo. Segundo Gil (2010) essas pesquisas têm como objetivo primordial a descrição das características de determinada população ou fenômeno ou, então, o estabelecimento de relações entre variáveis.

Apresenta uma abordagem quantitativa, com pesquisa de levantamento, que caracteriza-se pela interrogação direta das pessoas cujo comportamento se deseja conhecer (GIL, 2010), sendo que os dados foram coletados por meio de questionário, entre os meses de novembro de 2011 e maio de 2012.

Para o levantamento dos dados foram realizadas entrevistas estruturadas na forma de questionários, que tiveram como população-alvo suinocultores e avicultores ligados ao sistema de integração, com sua produção primária instalada nos municípios da Mesorregião Oeste de Santa Catarina. As variáveis estudadas na pesquisa foram a saúde e a socialização dos trabalhadores.

O universo deste estudo é constituído de suinocultores e avicultores ligados ao sistema de integração com as agroindústrias, instalados nos municípios da Mesorregião Oeste de Santa Catarina, distribuídos:

Quadro 1. Total de avicultores e suinocultores integrados.

\begin{tabular}{ccc} 
& Avicultor integrado & Suinocultor integrado \\
\hline Homens & 29 & 70 \\
Mulheres & 29 & 59 \\
\hline Total & 58 & 129 \\
\hline
\end{tabular}

Os estratos da população foram selecionados por modelos de produção 
desenvolvidos na propriedade, divididos em sexo masculino e feminino e em três faixas etárias diferentes. Portanto, a pesquisa foi estabelecida como não probabilística e de forma intencional (BARBETA, 2012), uma vez que se elegeram algumas categorias de produtores dentro da população pesquisada, estabelecendo um número de pesquisadores semelhantes para cada categoria, mas não necessariamente representativos estatisticamente dessa população.

Os dados foram analisados estatisticamente por meio do teste de associação qui-quadrado de Pearson. Este é o método estatístico mais antigo e mais usado em pesquisa social, que permite testar a significância da associação entre duas variáveis qualitativas, bem como comparar duas ou mais amostras, quando os resultados da variável resposta estão dispostas em categorias (BARBETTA, 2012). Como a pesquisa em questão possui itens cuja frequência observada em algumas classes é menor que cinco, utiliza-se, conforme recomendação de Conti (2013), a correção de continuidade proposta por Yates (1934), também conhecida como teste de $\mathrm{X}^{2}$ exato.

Para Siegel (1975), o primeiro passo no processo de tomada de decisão é a definição da hipótese nula $\left(\mathrm{H}_{0}\right)$. Para rejeitar a hipótese nula, utiliza-se usualmente a significância de 0,05 . Portanto, nessa pesquisa, são aceitos apenas os níveis de significância igual ou inferior a 0,05 , que corresponde estatisticamente a $95 \%$ de confiança.

Os resultados apresentados na pesquisa foram divididos em dois grupos: I) itens que demonstram a relação com a agroindústria e condições de trabalho; e II) itens que caracterizam a saúde de avicultores e suinocultores. Optou-se por dividir os fatores que compõem o item 1 para efeito de análise. Dessa maneira, os três grupos de itens identificados foram:

a) itens que demonstram as condições de trabalho;

b) itens que demonstram a relação com a agroindústria;

c) itens que caracterizam a saúde de avicultores e suinocultores.

Para cada um desses três grupos de itens, procurou-se identificar os itens que apresentavam maior observação de dados extremos em pelo menos um dos dois grupos de trabalhadores ("muito insatisfeito", "bastante", "extremamente", etc), 
com objetivo de considerar na análise aqueles itens que possuiriam maior efeito nas condições de trabalho de suinocultores e avicultores, chegando ao final a sete itens de grande influência. A esses itens foi adicionado um oitavo item de aspecto mais generalista, a renda familiar mensal, com intuito de verificar estatisticamente o efeito de possíveis discrepâncias salariais nas duas classes de trabalhadores.

\subsubsection{Itens que Demonstram as Condições de Trabalho}

a) Nível de cansaço: mais de 50\% de incidência de "bastante cansaço" ou "extremo cansaço" tanto por parte de suinocultores quanto por parte de avicultores;

b) Nível de satisfação da relação com o trabalho: escolhida pelo caráter generalista da pergunta, englobando uma série de fatores que correspondem à satisfação geral com o trabalho.

\subsubsection{Itens que Demonstram a Relação com a Agroindústria}

a) Nível de satisfação geral: escolhida pelo caráter generalista, definindo uma série de fatores que demonstram a satisfação geral com a integradora;

b) Satisfação financeira: aproximadamente $36 \%$ de suinocultores e $58 \%$ de avicultores insatisfeitos;

c) Conhecimento do cálculo do valor do lote: desconhecido por cerca de $64 \%$ dos suinocultores e $82 \%$ dos avicultores.

\subsubsection{Itens que Caracterizam a Saúde de Avicultores e Suinocultores}

a) "Incidência de problemas de saúde": cerca de metade dos trabalhadores estudados já tiveram problemas de saúde relacionados ao trabalho;

b) "Nível de depressão": cerca de 90\% dos trabalhadores dos dois grupos apresentam algum nível de depressão.

\section{RESULTADOS E DISCUSSÃO}


Os estudos permitiram observar diferenças visíveis entre as condições de trabalho de avicultores e dos suinocultores no Oeste catarinense. Estes dados fazem supor que as condições de trabalho e sociais dos avicultores são consideravelmente piores que as respectivas condições dos suinocultores.

Quanto ao nível de cansaço, mais de 70\% dos avicultores se declaram "bastante" ou "extremamente" cansados após jornada de trabalho, em relação a pouco mais de 50\% dos suinocultores, conforme exposto na Tabela 1.

Tabela 1. Percepção do nível de cansaço de suinocultores e avicultores.

\begin{tabular}{l|c|c}
\hline Nível de cansaço após dia de trabalho & Suinocultor (\%) & Avicultor (\%) \\
\hline Nada / Sem resposta & 1,61 & 1,7 \\
Muito Pouco & 15,59 & 0 \\
Mediano & 39,25 & 25,9 \\
Bastante & 15,59 & 50,0 \\
Extremo & 36,56 & 22,4 \\
\hline Total & $\mathbf{1 0 0}$ & $\mathbf{1 0 0}$ \\
\hline
\end{tabular}

Fonte: Elaborado pelos autores (2013).

O nível de depressão, evidenciado na Tabela 2, também aparece com maior incidência nos trabalhadores da avicultura.

Tabela 2. Percepção do nível de depressão de suinocultores e avicultores.

\begin{tabular}{lcc}
\hline Nível de depressão & Suinocultor (\%) & Avicultor (\%) \\
\hline Nunca & 5,64 & 10,17 \\
Muito Pouco & 45,64 & 37,29 \\
Mediano & 33,33 & 27,12 \\
Bastante & 14,36 & 23,73 \\
Extremo & 1,03 & 1,69 \\
\hline Total & $\mathbf{1 0 0}$ & $\mathbf{1 0 0}$ \\
\hline
\end{tabular}

Fonte: Elaborado pelos autores (2013).

Quanto ao nível de satisfação da relação com a empresa integradora, o grau 
de "insatisfação" e, sobretudo, de "muita insatisfação" é consideravelmente maior em avicultores que em suinocultores.

Tabela 3. Percepção de satisfação com empresa integradora.

\begin{tabular}{lcc}
\hline Nível de satisfação com integradora & Suinocultor (\%) & Avicultor (\%) \\
\hline Sem resposta & 13,18 & 1,72 \\
Muito Satisfeito & 0,78 & 0 \\
Satisfeito & 55,04 & 24,14 \\
Indiferente & 8,53 & 3,45 \\
Insatisfeito & 21,71 & 32,76 \\
Muito Insatisfeito & 0,78 & 37,93 \\
\hline Total & $\mathbf{1 0 0}$ & $\mathbf{1 0 0}$ \\
\hline
\end{tabular}

Fonte: Elaborado pelos autores (2013).

Ainda em relação à empresa integradora, observam-se também diferenças no que tange à satisfação com a relação financeira, conforme exposto na Tabela 4 .

Tabela 4. Percepção de satisfação financeira com a integradora.

\begin{tabular}{lcc}
\hline Nível de satisfação da relação financeira com integradora & $\begin{array}{c}\text { Suinocultor } \\
\text { (\%) }\end{array}$ & $\begin{array}{c}\text { Avicultor } \\
\text { (\%) }\end{array}$ \\
\hline Muito Satisfeito & 0 & 0 \\
Satisfeito & 51,28 & 34,36 \\
Indiferente & 12,82 & 8,47 \\
Insatisfeito & 34,36 & 30,51 \\
Muito Insatisfeito & 1,54 & 27,12 \\
\hline Total & $\mathbf{1 0 0}$ & $\mathbf{1 0 0}$ \\
\hline
\end{tabular}

Fonte: Elaborado pelos autores (2013).

Como era de se esperar, a maior insatisfação com a relação financeira por parte dos avicultores acompanha também uma maior incidência de desconhecimento de cálculo do valor do lote, que é realizado pela integradora. Essa situação é ilustrada na Tabela 5.

Tabela 5. Conhecimento do cálculo do valor do lote. 


\begin{tabular}{lcc}
\hline Conhecimento do cálculo do valor do lote & Suinocultor (\%) & Avicultor (\%) \\
\hline Sim & 35,93 & 17,24 \\
Não & 64,07 & 82,76 \\
\hline Total & $\mathbf{1 0 0 , 0 0}$ & $\mathbf{1 0 0 , 0 0}$ \\
\hline
\end{tabular}

Fonte: Elaborado pelos autores (2013).

Ainda há que se considerar um percentual maior de avicultores que recebem até $R \$ 1.000,00$ (menor faixa considerada na pesquisa) e também de $R \$ 1.000,00$ até $\mathrm{R} \$ 3.000,00$ (segunda menor faixa), conforme apresentam os dados da Tabela 6.

Tabela 6. Renda familiar mensal de suinocultores e avicultores.

\begin{tabular}{lcc}
\hline Renda familiar mensal (em R\$) & Suinocultor (\%) & Avicultor (\%) \\
\hline Mais de 11.000 & 12,70 & 6,35 \\
De 9.000 a 11.000 & 3,17 & 0 \\
De 6.000 a 9.000 & 8,47 & 3,17 \\
De 3.000 a 6.000 & 17,46 & 14,29 \\
De 1.000 a 3.000 & 26,46 & 52,38 \\
Menos de 1000 & 2,65 & 14,29 \\
Sem resposta & 29,10 & 9,52 \\
\hline Total & $\mathbf{1 0 0}$ & $\mathbf{1 0 0}$ \\
\hline
\end{tabular}

Fonte: Elaborado pelos autores (2013).

Quanto à satisfação em relação ao trabalho em si, o percentual de insatisfação dos avicultores é mais de três vezes maior que o grau de insatisfação dos suinocultores.

Tabela 7. Percepção de satisfação com a relação de trabalho.

\begin{tabular}{lcc}
\hline Nível de satisfação da relação de trabalho & Suinocultor (\%) & Avicultor (\%) \\
\hline Muito Satisfeito & 0,51 & 1,69 \\
Satisfeito & $\mathbf{7 8 , 4 6}$ & 49,15 \\
Indiferente & 7,18 & 6,78 \\
Insatisfeito & 13,33 & 30,51 \\
Muito Insatisfeito & 0,51 & 11,86 \\
\hline Total & $\mathbf{1 0 0}$ & $\mathbf{1 0 0}$ \\
\hline
\end{tabular}

Fonte: Elaborado pelos autores (2013). 
Na Tabela 8 é possível verificar que os avicultores também apresentam, quando comparados aos suinocultores, uma maior incidência de problemas de saúde relacionados ao trabalho. Enquanto os suinocultores apresentaram, na pesquisa, um índice de 30,69\% neste critério, os avicultores apresentaram a taxa de 55,56\% trabalhadores com problemas de saúde relacionados ao trabalho.

Tabela 8. Problemas de saúde relacionados ao trabalho.

\begin{tabular}{lcc}
\hline Incidência de problemas de saúde relacionados ao trabalho & $\begin{array}{c}\text { Suinocultor } \\
(\mathbf{\%})\end{array}$ & $\begin{array}{c}\text { Avicultor } \\
\mathbf{( \% )}\end{array}$ \\
\hline Sem resposta & 1,06 & 1,59 \\
Sim & 30,69 & 55,56 \\
Não & 68,25 & 42,86 \\
\hline Total & $\mathbf{1 0 0 , 0 0 \%}$ & $\mathbf{1 0 0 , 0 0 \%}$ \\
\hline
\end{tabular}

Fonte: Elaborado pelos autores (2013).

Com diferenças tão visíveis, realiza-se, então, o teste estatístico qui-quadrado para verificar quais dessas diferenças possuem validade estatística sem serem atribuídas ao acaso, com 95\% de nível de confiança. O número de graus de liberdade, a ser analisado, foi definido a partir da fórmula $\mathrm{GL}=$ (número de linhas-1) x (número de colunas-1). Definem-se então as hipóteses:

- Hipótese nula, $\mathrm{H}_{0}$ : não há associação entre os grupos, ou seja, as variáveis são independentes.

- Hipótese alternativa, $\mathrm{H}_{1}$ : há associação entre os grupos, ou seja, as variáveis são dependentes.

Se o $\mathrm{X}^{2}$ encontrado for menor que o $\mathrm{X}^{2}$ tabelado, então aceita-se $\mathrm{H}_{0}$ e as variáveis são independentes. Se o $\mathrm{X}^{2}$ encontrado for maior que $\mathrm{o} \mathrm{X}^{2}$ tabelado, mesmo após a correção de Yates, então existe dependência entre as variáveis considerando o nível de significância igual a 0,05 .

Após análise dos oito fatores citados, foram encontrados os valores apresentados na Tabela 9. 
Tabela 9. Análise dos Fatores Pesquisados

\begin{tabular}{|c|c|c|c|c|c|}
\hline Fator analisado & $\begin{array}{c}\text { Grau de } \\
\text { Liberdade }\end{array}$ & $\begin{array}{c}\mathrm{X}^{2} \\
\text { tabelado }\end{array}$ & $\begin{array}{c}\mathrm{X}^{2} \\
\text { encontrado }\end{array}$ & $\begin{array}{r}\text { Correção } \\
\text { de Yates }\end{array}$ & $\begin{array}{l}\text { Valor-p com } \\
\text { correção } \\
\text { de Yates }\end{array}$ \\
\hline Nível de cansaço & 4 & 9,49 & 10,0783776 & 7,252594 & $0.10-0.15$ \\
\hline Nível de depressão & 4 & 9,49 & 5,2362926 & 3,653449 & $0.25-0.50$ \\
\hline $\begin{array}{l}\text { Nível de satisfação } \\
\text { geral com integradora }\end{array}$ & 4 & 9,49 & 58,6218938 & 53,05598 & $<0.0005$ \\
\hline $\begin{array}{l}\text { Nível de satisfação da } \\
\text { relação financeira }\end{array}$ & 4 & 9,49 & 43,4446492 & 39,3227 & $<0.0005$ \\
\hline $\begin{array}{l}\text { Conhecimento do cál- } \\
\text { culo do valor do lote }\end{array}$ & 1 & 3,84 & 7,01399521 & 6,169186 & $0.01-0.02$ \\
\hline Renda familiar mensal & 6 & 12,59 & 34,499106 & 28,48082 & $<0.0005$ \\
\hline $\begin{array}{l}\text { Nível de satisfação } \\
\text { da relação com o } \\
\text { trabalho }\end{array}$ & 4 & 9,49 & 34,499106 & 28,48082 & $<0.0005$ \\
\hline $\begin{array}{l}\text { Incidência de proble- } \\
\text { mas de saúde relacio- } \\
\text { nados ao trabalho }\end{array}$ & 3 & 11,07 & 12,9517508 & 11,89054 & $0.005-0.01$ \\
\hline
\end{tabular}

Fonte: Elaborado pelos autores (2013).

Portanto, os dois fatores que estatisticamente podem ser considerados independentes são o nível de cansaço e o nível de depressão, uma vez que os valores de p superaram o nível de confiança estabelecido de $95 \%(p=0,05)$. Todos os demais fatores apresentam diferenças estatísticas significativas, sendo dependentes por terem nível de significância maior que $95 \%$ ( $p>0,05)$.

O nível de cansaço foi o único dos oito fatores que a correção de Yates alterou a análise, visto que o método qui-quadrado sugere a aceitação de dependência entre os valores. Porém, como neste item houve frequências observadas menores que cinco para um ou mais itens, optou-se pela correção de Yates.

O nível de depressão foi o único fator que o cálculo qui-quadrado por si só já evidenciou independência entre os dados. Logo, não se pode afirmar que as piores condições relatadas pelos avicultores nas respostas estejam relacionadas direta- 
mente a uma maior incidência de depressão nesse grupo, pois o resultado estatístico sugere uma aleatoriedade para esse fator.

A análise das questões referentes à relação com a empresa integradora evidencia estatisticamente que a relação dessas com os suinocultores é melhor do que a relação com os avicultores. Os dois itens que possuíram maior $\mathrm{X}^{2}$ estão ligados a essa relação, sugerindo que de fato há grandes diferenças entre os dois grupos na percepção que esses possuem das empresas integradoras e o grau de satisfação geral e financeiro.

Os avicultores também possuem renda consideravelmente menor, e há maior incidência de desconhecimento do cálculo do valor do lote, porém não são, necessariamente, fatores geradores de maior cansaço ou de depressão por parte dos avicultores.

Embora apresentem resultados aparentemente piores em todos os quesitos, sugere-se que o foco para a mudança desse cenário seja principalmente na relação das integradoras com os produtores, e que os fatores que fazem com que essa relação seja significativamente melhor entre os suinocultores possa servir de exemplo para melhorar as condições sociais dos avicultores.

Os avicultores, de fato, relatam que os contratos com as agroindústrias integradoras são unilaterais. As empresas determinam os valores a serem pagos nos lotes e descontam no preço pago aos produtores os custos que possuem no fornecimento de ração e medicamentos usados na criação. O lucro incerto e a falta de autonomia na relação de trabalho faz com que os avicultores tenham dúvidas na continuidade da atividade, e consideram a suinocultura como possibilidade (DELOS ASSOCIADOS, 2012).

Com diferenças tão evidentes, comprovadas estatisticamente, as agroindústrias integradoras da avicultura passam pelo risco de perderem os avicultores para outros setores, dentre eles a suinocultura, caso não tenham a iniciativa de liderar ações que promovam a melhoria das condições de trabalho de seus colaboradores. A dificuldade de negociação por parte dos avicultores e desconhecimento financeiro sugere também a importância de intervenções governamentais que possibilitem uma maior educação financeira aos produtores.

Os dados demonstrados neste artigo destinam-se, sobretudo, a dois grupos: 
às agroindústrias integradoras, no sentido de alertá-las à necessidade de uma relação mais aberta e amistosa com os avicultores, e ao Governo, visto ser esse um setor estratégico à economia catarinense, em seu papel de equilibrar relações de trabalho. É interesse que ambos os grupos possam contar com profissionais mais qualificados, motivados e que tenham a visão das agroindústrias também como parceiras na busca de resultados melhores para o setor, o que passa diretamente pelo bem-estar dos avicultores.

\section{CONSIDERAÇÕES FINAIS}

A análise das relações e condições de trabalho e de saúde dos agricultores vinculados à produção industrial de suínos e aves, e como estas interferem no bem -estar e reprodução social dessa categoria e na sustentabilidade do complexo agroalimentar do Oeste catarinense permitiu perceber que existiam condições de trabalho e sociais muito piores por parte dos avicultores em relação aos suinocultores. Nesse sentido, foi analisado estatisticamente, por meio do teste de hipóteses e qui-quadrado de Pearson, se há, de fato, diferença significativa nos resultados encontrados nesses dois grupos de produtores.

As análises levam a concluir que as questões referentes à relação com a empresa integradora revelam uma melhor relação com os suinocultores, sugerindo que de fato há grandes diferenças entre os dois grupos na percepção que esses possuem das empresas integradoras e, também, o grau de satisfação geral e financeiro. Os avicultores também possuem renda consideravelmente menor, e têm maior incidência de desconhecimento do cálculo do valor do lote, porém não são necessariamente fatores geradores de maior cansaço ou de depressão por parte dos avicultores.

Identificar os motivos que levam a resultados tão díspares e trabalhar para que efetivamente o cooperativismo faça parte da relação é um dos enfoques a serem tratados na região. Sugere-se também uma análise da lei que envolve esse tipo de relação de trabalho. Estaria ela sendo cumprida pelos integradores?

As diferenças entre os dois tipos de produtores pode ser também um alerta para todo o setor relacionado à atividade avicultora, pois comparativamente um produtor parece ter menos motivos para "apostar" nesse tipo de atividade. As inte- 
gradoras devem buscar oportunizar relações melhores com os produtores, e estes devem se organizar para aumentar sua representatividade frente ao grupo gestor.

\section{REFERÊNCIAS}

ABRAMOVAY, R. Agricultura familiar e o uso do solo. São Paulo em Perspectiva, v. 11, n. 2, p. 73-78, 1997.

BARBETTA, P.A. Estatística aplicada às ciências sociais. 8. ed. rev. Florianópolis: Ed. da UFSC, 2012.

COLETTI, T. Agroindústria suinícola e agricultura familiar: uma crônica sobre a trajetória histórica no oeste catarinense. Florianópolis: Universidade Federal de Santa Catarina, 2009.

CONTI, F. Biometria Qui Quadrado: leitura complementar ao capítulo 3. Laboratório de Informática - ICB - UFPA. Disponível em: < http://www.ufpa.br/dicas/biome/ biopdf/bioqui.pdf > . Acesso em: 05 fev. 2013.

DELOS ASSOCIADOS. Análise das relações e condições de trabalho e de saúde dos agricultores vinculados à produção industrial de suínos e aves, e como estas interferem no bem-estar e reproduçáo social desta categoria e na sustentabilidade do complexo agroalimentar do oeste catarinense. Florianópolis: Delos Associados, 2012. (Relatório da pesquisa, projeto de cooperação técnica BRA/ IICA/10/001).

GIL, A.C. Como elaborar projetos de pesquisa. 5. ed. São Paulo: Atlas, 2010.

GOULARTI FILHO, A. Formação econômica de Santa Catarina. 2. ed. rev. Florianópolis: Ed. da UFSC, 2007.

MELLO, M.A.; SCHMIDT, W. A agricultura familiar e a cadeia produtiva do leite no Oeste catarinense: possibilidades para a construção de modelos heterogêneos. In: PAULILO, M.I.S.; SCHMIDT, W. (Org.). Agricultura e espaço rural em Santa Cata- 
rina. Florianópolis: Ed. da UFSC, 2003.

PAULILO, M.I.S. A Integração do Sul do Estado de Santa Catarina. 1987. Tese (Doutorado) - Universidade Federal do Rio de Janeiro, Instituto de Antropologia Social do Museu Nacional, Rio de Janeiro, 1987.

SERVIÇO DE APOIO ÀS MICRO E PEQUENAS EMPRESAS SANTA CATARINA. Santa Catarina em números: oeste. Florianópolis: Sebrae/SC, 2010. Disponível em: $<$ http://www.sebrae-sc.com.br/scemnumero/arquivo/Regional-Oeste.pdf $>$. Acesso em: 25 fev. 2013.

SIEGEL, S. Estatística não paramétrica (para as ciências do comportamento). São Paulo: McGraw-Hill, 1975.

YATES, F. Contingency table involving small numbers and the $\mathrm{X}^{2}$ test. Journal of the Royal Statistical Society, v. 1, p. 217-235, 1934.

Recebido em: 18 de março de 2014 Aceito em: 22 de maio de 2015 